\title{
Alternative-Renewable Energy Complex on the University Base
}

\author{
Ahmad Valiyev ${ }^{1}$, Etibar Rzazadeh ${ }^{1,}$, , Nuru Safarov ${ }^{2}$, Samira Cafarova $^{1}$ \\ ${ }^{1}$ Educational Technopark, Odlar Yurdu University, Baku, Azerbaijan \\ ${ }^{2}$ Department of Electronics and Telecommunications Engineering, Khazar University, Baku, Azerbaijan
}

Email address:

erzazadeh@yahoo.com (E. Rzazadeh)

${ }^{*}$ Corresponding author

\section{To cite this article:}

Ahmad Valiyev, Etibar Rzazadeh, Nuru Safarov, Samira Cafarova. Alternative-Renewable Energy Complex on the University Base. American Journal of Embedded Systems and Applications. Vol. 5, No. 5, 2017, pp. 39-43. doi: 10.11648/j.ajesa.20170505.12

Received: November 11, 2017; Accepted: November 20, 2017; Published: January 2, 2018

\begin{abstract}
Creation of local alternative energy complexes can provide serious assistance to the development of alternative energy sphere in Azerbaijan by the ratio of the educational process and research work. Such complexes are favorable from the point of view of research of renewable energy problems of the republic networks. The issue of creating a common electronic catalog on alternative energy sources in Azerbaijan can be solved through such network.
\end{abstract}

Keywords: Alternative Energy, University Complex, Techno Park, Solar Cells, Scheme, Computerization

\section{Introduction}

In addition to educational demonstration functions the educational research complex of the alternative energy of the University should also serve as scientific research for this type of problem. This problem is considered as a multiparameter problem. Solution of this problem on the territory of Azerbaijan, characterized by various relief climatic indicators makes it necessary to collect a large number of indicators from different parts of this country. At the same time multilateral processing is considered for searching and then processing and transferring of information as additional data in a computer network. At the initial stage the possibilities of programming schedules are used for the creation of reports and diagrams. At the next stage the appropriate software package should be created and applied. For installation and maintenance of software, the participation of University masters is associated with the implementation of practical training programs [1-5].

Providing accurate and rich information about the main type of alternative energy sources for different climatic zone and regions is main task for the implementation of mechanism for managing alternative energy sources. As a result, it will be possible to compile full - fledged energy maps on a large scale. Here, the solution of new energy problems consists of the collection and processing of indicators taken from different characteristic areas of the territory of Azerbaijan, as well as operational control on them [6-8]. Taking into consideration importance and usefulness the developed methods, the acquisition of the most important energy indicators, first of all for Azerbaijan (solar radiation, wind energy, at the next stage temperatures of sources of geothermal water, kinetic indicators of small and large rivers, the volume of secondary combustion products, energy balance of carbohydrates collected at the bottom of the reservoirs and etc.) is planned.

\section{Problem Statement}

The organization of the planned work is divided into the following stages: creation of local alternative energy complexes on the basis of correlation of the educational process with research work in advanced higher educational institutions; creation and development of the circuit diagram of the basic global computer places network (the workstation installation are assigned, database of parameters collected from the entire territory and also the circuit diagram of its use are prepared on the main computer; selection of important indicators for the given items and collection and preparation of technologies for their input into the computer; creation and 
test of the complex of devices for the input important energy computer parameters across the country; creation of the necessary software complex and database.

During the design of solar power plants it is necessary to study the duration of isolation that is, direct sunlight on solar modules. Dense arrangement of solar modules and its use for concentrated solar photomodulators with a complex shape is very complicated although the graphical method is basic here. In such circumstances it is possible to use certain computer algorithms preparing a report about isolation. At the initial stage the soliworks programis are used for this task. At the next stage, the creation of a network throughout the country also provides an apportunity to calculate the duration of isolation automatically [9].

Alternative or renewable energy means that it is practically inexhaustible clean energy sources. Traditionally alternative sources of energy are: solar energy, wind energy, backwater - retreat, energy of rivers, geothermal, bio-fuels

The third day - the sources of energy mentioned except energy of backwater- retreat, are used at different levels depending on the region of Azerbaijan and its economic indicators. In fact, the sources of "clean" energy that have been widely used since the last century are shown in this small list. They become important in a period when, on the one hand, the price of carbohydrates increased sharply, and one the other hand the ecological situation becomes more complicated. It should be noted that the original source of all these types of energies is the same - Sun, despite the different ways and purposes of their usage. For instance, as it is known there is a lot of information about the use of wind engines in ancient Egypt, China, Japan, Tibet and other ancient cultural centers in prehistoric times. Besides Azerbaijan is one of the first in the use of oil as fuel, there are a lot of facts about the use of energy wind and water with the help of primitive converters in the most ancient ties. It is known that $2 * 10^{18} \mathrm{~kW}$ of light energy falls to the Earth from the Sun per year. And it is 30000 times more than energy used by people around the world, 35\% of the solar energy falling into the Earth atmosphere returns to space. The rest of the solar energy is spent on heating the Earth surface, evaporation in the hydrosphere. It was calculated that sun rays falling perpendicularly on $1 \mathrm{~cm}^{2}$ of the Earth surface give about 1.4 calorie of hest per minute. With the complete conversion of this quantity into mechanical work at this work of 4270 coulee, sun rays falling perpendicularly per $1 \mathrm{~km}^{2}$ on the Earth surface every second produce approximately 1000 coulee. Thus, depending on climatic conditions and geographical latitude, the average annual energy of sun rays on the Earth surface is $100-250 \mathrm{~kW} / \mathrm{m}^{2}$.

In addition, intensive scientific works on many new sources of energy is being carried out worldwide. In addition to such exotic source of energy, as gravitational, magnetic, ostic energy, the use of ancient means at a new level is an actual scientific and technical problem. In Azerbaijan the use of sea-wave energy in the near future will become one of the promising tasks. Although here the rich sources of oil and gas reduce the severity of the energy problem, but at the same time a tense ecological situation makes these problems topical. In addition to academic duties, the opportunities of universities for research in this field are indispensable $[10,11]$.

The alternative energy complex of Odlar Yurdu University is focused on the above - mentioned problems. The complex contains solar and wind photocells, a solar concentrator, a vacuum solar water health and devices for a thermal electric converter. These devices are connected in a single integrated form and computerized. The current state of each device must always be controlled by a computer program. The information is periodically sent to the computer screen and displayed as a graph and a table. At the same time, the necessary parameters are displayed in the database "Alternative energy" and pre periodically updated automatically. The software package developed in the research laboratory of the technological park is aimed at performing the following functions: operational multilevel presentation of information stored in the database; periodic analysis in the database (as needed), managing the work of an alternative energy complex, preparation of automatic recommendations using the forecasting unite.

In contrast to the corresponding systems of industrial significance the alternative energy complex of the University is focused on the implementation of educational representative and observational research functions. Therefore, additional devices were created to demonstrate the work of these devices. These devices clearly reflect the amount of received energy, on the other hand they point to the possibility of real use of renewable energy. As a rule they consist of computer elements which are available to students. For instance, the energy transfer capabilities of solar photocells are shown on the stand reflecting a single board with different nominal electric rings. (Figure 1)

An electric current of $3 ; 5 ; 12 \mathrm{~V}$ is output from the power supply unit of decommissioned personal computer. At the same time the $15-17.5 \mathrm{~V}$ voltage is taken from $2 \mathrm{~V}$ photocells mounted on the stand at a height of 5 meters. A small display is installed to demonstrate the energy received on the stand.

To illustrate these energy possibilities, a cooler used to cool the computer processor is connected to the stand. The energy voltage received from the Sun and changing depending on the light is reflected on the display of multimeter. Observers can see how the voltage obtained by turning the photocell to the Sun changes. The vacuum solar water heater supplies canteen of the University with warm water. On sunny days the temperature of water in the tank of the device can reach up to $80^{\circ} \mathrm{C}$ and this heat is stored for 72 hours. Thermoelectric converters are used to use thermal energy of additional hot water. The received energy can be used for cooling the territory of canteen in summer (thermal energy is converted into electrical energy by means of semiconductors converters, and in turn electrical energy is used for cooling of the room's temperature), and in winter it can be used for heating. According to the calculations during the day it is possible to get an average $25 \mathrm{~V}$ from this device. 

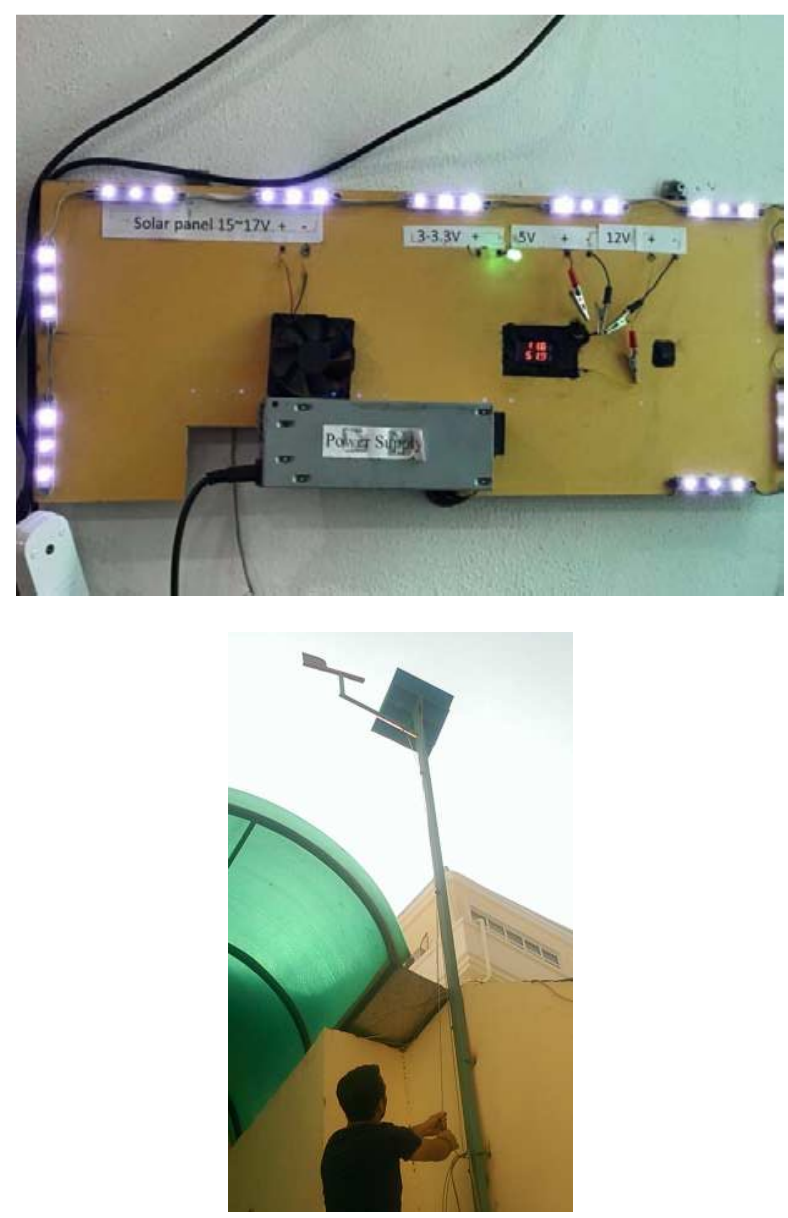

Figure 1. The energy transfer capabilities of solar photocells.

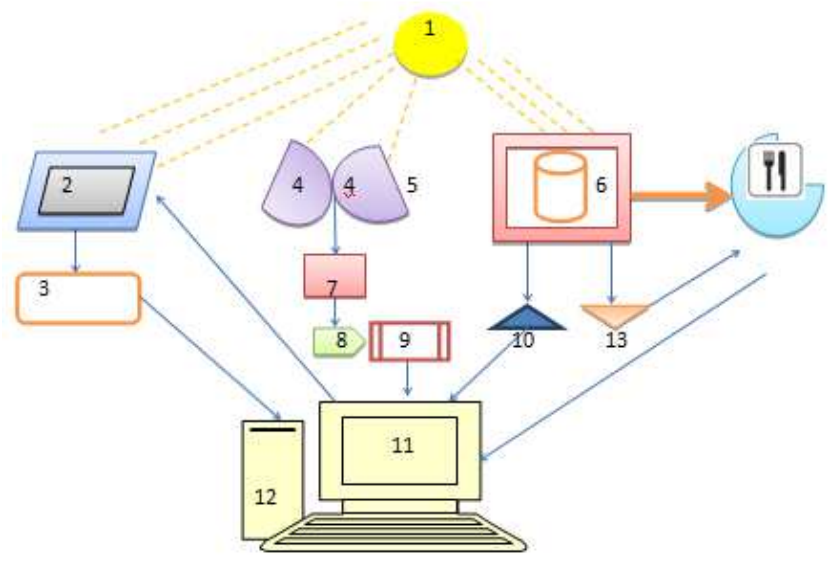

Figure 2. Scheme of solar energy converters.

1- the Sun, 2-converts solar energy into electrical energy, 3-energy stand, reflects the voltage variation got relatively to the angle of incidence of the solar radius of photocells, 4-solar hub, collects energy that falls on its surface and directs it to the photocells, 5-vacuum solar water heater, 6network of hot water supplies top of $80^{\circ}$ in the canteen, 7-battery, 8controller, 9-HUB, USB-distributes $5 \mathrm{~V}$ electricity to 6 outputs provided with diodes, 10-temperature sensors transmit the temperature indicators to the computer, 11-the monitor reflects the energy parameters, 12-energy parameters are periodically collected in a database located in the HDD of the computer, 13-heat-electrical converter.

The Purchase of electric energy is based on Zeebek effect on this device. So, contact place of closed loop consisting of different wires are kept in different temperatures, in this situation thermoelectric motion appears. The circle consisting of two different wires is called thermocouple or thermoelement. The emerging price of thermoelectric power in the original approach depends only on wire material, and on temperature of hot and cold contacts.

In a small range price for thermoelectric power can be considered proportional to the temperature difference: $E=$ $\alpha_{1,2}\left(T_{2}-T_{1}\right)$

$E$ - thermoelectric ability of a pair; $T_{2}-T_{I}$-the difference in temperature in the contacts; $\alpha_{1,2}$-coefficient of thermoelectric driving force; In the simplest case the coefficient of thermoelectric driving force is assigned only by the material of the wires. At the same time the coefficient of thermoelectric driving force depends on the temperature. In some cases the temperature change may change $\operatorname{sign} \alpha_{I, 2}$.

More accurate expression of the coefficient of the thermoelectric driving force is shown in accordance with the following scheme:

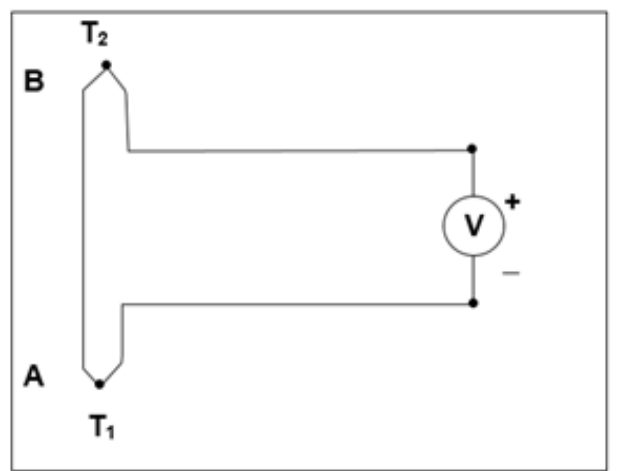

Figure 3. Thermocouple.

$$
V=\int_{\mathrm{T} 1}^{\mathrm{T} 2}\left(S_{B}(T)-S_{A}(T)\right) d T
$$

Here, $S_{B}(T)$ and $S_{A}(T)$ are the functions of the temperature dependence of the electric potential at suitable ends. When the difference in the temperature of the contacts reaches from $100^{\circ} \mathrm{C}$ - to $0^{\circ} \mathrm{C}$, in the case the estimate of the thermoelectric motion is measured in millivolts. For instance, copper constant couple gives $4.5 \mathrm{mV}$ electric current, platinum rock $0.643 \mathrm{mV}$, nichrome - nickel $-4.1 \mathrm{mV}$.

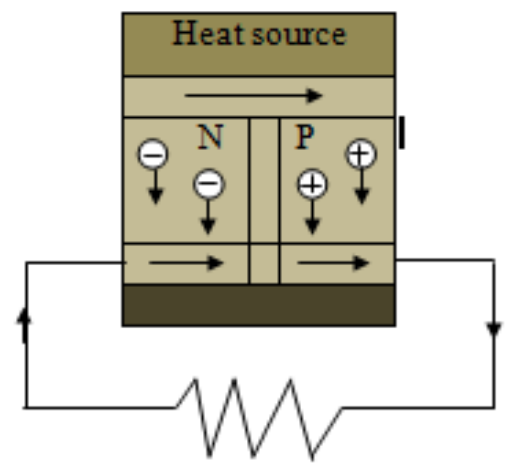

Figure 4. Scheme of thermoelectric motion. 
The producing of energy that can be obtained from climatic zones of Azerbaijan is shown in the following table: photovoltaic devices as a source of alternative energy for the

Table 1. Annual private electricity production $\left(\mathrm{kW}^{*}\right.$ hour $\left./ \mathrm{m}^{2}\right)$.

\begin{tabular}{lll}
\hline Climatic zones & Latitude & Fixed flat photovoltaic module directed to the south and horizontally positioned at an angle of $45^{\circ}$ \\
\hline Sheki - Zagatala area & 41,3 & 193,9 \\
Sheki - Shamakhi area & 41,0 & 202,4 \\
Guba-Khachmaz area & 41,3 & 205,9 \\
Gilyazi - Dubrar area & 40,9 & 204,0 \\
Northern part of the Small Caucasus & 40,5 & 205,5 \\
Nackchivan region & 39,2 & 245,4 \\
Lankaran region & 38,8 & 210,7 \\
Kura Araz area & 40,0 & 230,3 \\
Absheron area & 40,3 & 208,9 \\
\hline
\end{tabular}

The mechanism of managing alternative energy sources in Azerbaijan should be quite flexible and favorable for access to information for people working in this field. From this point of view we are faced with the problem of creating a single electronic catalog about alternative energy in Azerbaijan.

According to the world practice the following parameters should be included in this catalog (the estimation in the table is given for the Absheron climatic zone).

Table 2. Average duration of the day of the month (hours).

\begin{tabular}{|c|c|c|c|c|c|c|c|c|c|c|c|c|}
\hline Months & January & February & March & April & May & June & July & August & September & October & November & December \\
\hline Average & 9,63 & 10,69 & 11,98 & 13,33 & 14,52 & 15,09 & 14,87 & 13,91 & 12,61 & 11,20 & 9,99 & 9,42 \\
\hline
\end{tabular}

Table 3. The average monthly estimation of cloudy days (\%).

\begin{tabular}{|c|c|c|c|c|c|c|c|c|c|c|c|c|}
\hline Months & January & February & March & April & May & June & July & August & September & October & November & December \\
\hline 10 -year average & 78,8 & 81,2 & 83,2 & 84,3 & 79,1 & 71,9 & 68,6 & 67,3 & 61,8 & 69,4 & 78,4 & 76,7 \\
\hline
\end{tabular}

Table 4. The average monthly wind speed at a height of $50 \mathrm{~m}$ from the ground $(\mathrm{m} / \mathrm{s})$.

\begin{tabular}{|c|c|c|c|c|c|c|c|c|c|c|c|c|}
\hline Months & January & February & March & April & May & June & July & August & September & October & November & December \\
\hline 10-year average & 7,75 & 8,72 & 8,43 & 8,02 & 7,56 & 7,83 & 8,80 & 8,89 & 8,13 & 8,09 & 8,55 & 8,72 \\
\hline
\end{tabular}

Table 5. Minimum and maximum wind speed conditions at a height of $50 \mathrm{~m}$ from the ground (\%).

\begin{tabular}{|c|c|c|c|c|c|c|c|c|c|c|c|c|}
\hline Months & January & February & March & April & May & June & July & August & September & October & November & December \\
\hline Minimum & -17 & -21 & -11 & -11 & -13 & -10 & -8 & -9 & -8 & -6 & -12 & -11 \\
\hline Maximum & 23 & 18 & 16 & 6 & 17 & 16 & 10 & 12 & 6 & 7 & 14 & 13 \\
\hline
\end{tabular}

Table 6. The average monthly wind speed at a height of $10 \mathrm{~m}$ from the ground $(\mathrm{m} / \mathrm{s})$.

\begin{tabular}{|c|c|c|c|c|c|c|c|c|c|c|c|c|}
\hline Months & January & February & March & April & May & June & July & August & September & October & November & December \\
\hline 10-year average & 6,34 & 6,87 & 6,67 & 6,40 & 5,97 & 6,20 & 6,98 & 6,99 & 6,45 & 6,41 & 6,79 & 6,92 \\
\hline
\end{tabular}

Table 7. The average estimation of monthly insulation on a horizontal surface $\left(\mathrm{kW}^{*} \mathrm{hour} / \mathrm{m}^{2} /\right.$ day) .

\begin{tabular}{|c|c|c|c|c|c|c|c|c|c|c|c|c|}
\hline Months & January & February & March & April & May & June & July & August & September & October & November & December \\
\hline 10-year average & 1,76 & 2,38 & 3,47 & 4,33 & 5,16 & 5,82 & 5,43 & 4,79 & 4,27 & 2,97 & 1,96 & 1,59 \\
\hline
\end{tabular}

Table 8. The average estimation of monthly insulation on a horizontal surface of the atmosphere ( $\left.\mathrm{kW}^{*} \mathrm{hour} / \mathrm{m}^{2} / \mathrm{day}\right)$.

\begin{tabular}{|c|c|c|c|c|c|c|c|c|c|c|c|c|}
\hline Months & January & February & March & April & May & June & July & August & September & October & November & December \\
\hline 10-year average & 2,61 & 3,76 & 5,41 & 6,76 & 7,82 & 8,22 & 7,73 & 6,74 & 5,69 & 4,35 & 2,96 & 2,29 \\
\hline
\end{tabular}

\section{Conclusions}

For the development of alternative energy in Azerbaijan, first of all, it is necessary to obtain information on energy parameters in different regions of the republic. From this point of view, alternative energy educational research complex of the University is one of the most promising means. And in turn, it means that the creation of a regional computer network is a modern way of solving problem for collection and analysis of energy data. Control of the global network and indicators of the necessary parameters to optimize its work are prepared and it is possible to send the received information to the main computer and feedback. The University is an additional clean energy source and along with that it is widely used in the educational process but also in the shortest possible time it can justify itself being economically viable. 


\section{References}

[1] R. S. Madatov, A. M. Hashimov, N. A. Safarov, G. M. Ahmadov. Calculation method and results of electricity production by solar photoelectrical devices for the Azerbaijan climatic zones. Power Engineering Problems, 2003 v. 20 (6); pp. 6 .

[2] N. A. Safarov, F. N. Tatardar, S. S. Amirov. The Hybride Composites Based New Materials For The Electromechanical And Acoustico-Electrical Converters. Journal of Non-Oxide Glasses. 2017, Vol 9 (1), pp. 19-23.

[3] N. Safarov, G. Axmedov, S. Axmedov. Investigations of Mathematical Models in Solar Collectors. American Journal of Energy Engineering, 2014, Volume2, Issue3, pp. 75-79.

[4] Nuru Safarov. Polymer - Silicon Sensor for Determination Flow. Global Journal of Engineering Science and Research Management. 3 (9): September, 2016, vol. 3, no. 9, pp. 19-21.

[5] A. A. Bayramov, N. A. Safarov Automatic Photoelectric Device for Most Optimum Illumination of Objects, ICCES International Conference on Computational \& Experimental Engineering and Sciences, 2008, vol. 5, no. 3, pp. 173-178.

[6] A. A. Bayramov, A. M. Hashimov, N. A. Safarov, F. J. Safarova. A solar power plant with a high performance solar cells and thin concentrators made of aluminum backed epoxy coated polymers. - Proc. TPE-2006, 2006, pp. 29-31.

[7] N. Safarov, G. Axmedov, S. Axmedov. Investigations of Mathematical Models in Solar Collectors. American Journal of Energy Engineering, 2014, Volume2, Issue3, pp. 75-79.

[8] R. M. Osmanzade, E. M. Rzazadeh. Globalization and energy, Baku, 2005 pp. 227 (in Russian).

[9] F. G. Aliev, E. M. Rzazadeh, N. A. Safarov, I. Q. Aliev, N. N. Mursakulov. Basic construction for solar power plants. 10-th Baku Intern. Congress "Energy, Ecology, Economy", 23-25 September, Baku, 2009, pp. 93-96.

[10] F. G. Aliev, N. A. Safarov, E. M. Rzazadeh. Computer network, gathering and analysis of ecoenergetic parameters of Azerbaijan Republic. Eighth Baku International Congress "Energy, Ecology, Economy" 1-3 June 2005 - Baku, Azerbaijan, pp. 202-206.

[11] E. M. Rzazadeh. N. A. Safarov. Monitoring of intensity of electromagnetic radiation. 3nd Inter. Conference on Technical and Physical Problems in Power Engineering, May 29-31, 2006 Ankara, Turkey, pp. 687-689. 